\title{
Мотивация к обучению в период средней взрослости
}

\author{
Анастасия С. Бузинова*, Юлия А. Аыкина \\ Южный фредеральный университет, г. Ростов-на-Аону, Россия \\ *E-mail: buzinovaanastasia@gmail.com
}

\begin{abstract}
Аннотация
Авторами Аоказывается актуальность исследования мотивации обучения в периоА среАней взрослости. Новизна заключается в том, что исслеАуется мотивация к обучению ^юдей, чей возраст уже не предполагает обучение. Как правило, ^юАи в периол среАней взрослости состоялись как личностно, так и профрессионально. Анализ научной митературы показал, что в основном исслеАователи изучают мотивацию к обучению ^иц 18-25 ^ет, т. е. в периол ранней взрослости, в ходе получения среднего специального, профрессионального и высшего образования. Предпринятое авторами исслеАование направлено на изучение мотивации к обучению в периол среАней взрослости (30-42 года).

В соответствующем разделе описываются методики, при помощи которых было проведено исследование мотивации к обучению в период средней взрослости (Н. Ц. БаАмаевой, Т. И. Ильиной, Е. Ветлужских).

Основными результатами исслеАования стали выводы о том, что мотивами обучения в периол средней взрослости служат: овладение профрессией, приобретение знаний и получение Аиплома. Мотивы самореализации, принесение пользы обществу, членам семьи, а также мотивы избегания (обучаются только чтобы не потерять работу) находятся на низких позициях, не являются настолько значимыми, как профрессиональные, знаниевые и статусные мотивы.

Таким образом, авторы рассмотрели основные компоненты мотивации к обучению у ююАей в периол среАней взрослости.

В заключение сАелан вывоА О том, что эорорективность обучения у ииц в периоде среАней взрослости Аовольно высока, т. к. уних присутствует заинтересованность в получении результата.
\end{abstract}

\section{КАючевые слова}

периол средней взрослости, обучение, мотивация, мотивы, профрессия, центр занятости населения, переобучение, интемектуальное развитие, образование, Аиплом

Аля цитирования: Бузинова А. С., Аыкина Ю. А. Мотивация к обучению в периоА средней взрослости // Северо-Кавказский психологический вестник. 2020. №18/2. С. $65-76$. doi: $10.21702 / \mathrm{ncpb} .2020 .2 .5$ 


\title{
Motivation for learning in middle adulthood
}

\author{
Anastasia S. Buzinova*, Yulia A. Dykina \\ Southern Federal University, Rostov-on-Don, Russia \\ * Corresponding author. E-mail: buzinovaanastasia@gmail.com
}

\begin{abstract}
The authors prove the relevance of the study of learning motivation in middle adulthood. The novelty lies in the fact that the study examines the motivation for learning of people whose age no longer implies learning. As a rule, people in the period of middle adulthood are accomplished both personally and professionally.

An analysis of the scientific literature has shown that researchers mainly study the motivation for learning of people aged 18-25, that is, in the period of early adulthood, during secondary special, professional and higher education. The research undertaken by the authors is aimed at studying the motivation to learn during middle adulthood (30-42 years). In the corresponding section describes the methods by which a study was conducted on motivation for learning in the period average maturity: N. Ts. Badmaeva, T. I. Il'ina, E. Vetluzhskih.

The main results of the study were the conclusions that the motives for learning during middle adulthood are: mastering a profession, acquiring knowledge and obtaining a diploma. The motives of self-realization, bringing benefits to society, family members, as well as the motives of avoidance (they are trained only to avoid losing their jobs) are in low positions, and are not so significant as professional, knowledge, and status motives. Thus, the authors considered the main components of motivation to learn in people during middle adulthood.

In conclusion, it is concluded that the effectiveness of training in individuals in the period of middle adulthood is quite high, since they have an interest in getting results.
\end{abstract}

\section{Keywords}

middle adulthood, training, motivation, motives, profession, employment center, retraining, intellectual development, education, diploma

For citation: Buzinova A. S., Dykina Yu. A. Motivation for learning in middle adulthood. Severo-Kavkazskii psikhologicheskii vestnik = North-Caucasian Psychological Bulletin, 2020, no. 18/2, pp. 65-76. doi: 10.21702/ncpb.2020.2.5 (in Russ.).

\section{ВВЕДЕНИЕ}

Значимость мотивации как ведущей проблемы отечественной и зарубежной психологии связана с анализом поведенческих мотивов человека, которые побуждают его к той или иной деятельности. 
Рассматривая мотивацию к обучению, следует сказать, что она тесно связывается с потребностью человека и определенной целью. Между тем сам процесс обучения довольно важен как деятельность, позволяющая человеку оставаться в рамках общества, в котором он находится. Так мы подходим к важности вопроса особенностей мотивации к обучению с учетом возрастных особенностей, потому что в разные периоды жизни у людей могут быть различные мотивы для обучения [1].

Наиболее продолжительная часть жизни человека - период взрослости, в который возникает множество возрастно-психологических и социально-психологических проблем, обуславливающих особенности мотивации. Однако на сегодняшний день проблема особенностей мотивации рассматриваемого периода жизни является одной из наименее разработанных, причиной чего является существующая для исследователей трудность, заключающаяся в отсутствии единой теории взрослости и наличии множества разнообразных ее определений. В большинстве классификаций период взрослости начинается с 18-20 лет и заканчивается 55-60 годами. Д. Б. Бромлей внутри указанного периода также выделяет следующие периоды: «18-25 лет-ранняя взрослость; 25 - 40/45 лет - средняя взрослость и 40/45 - 55/60 лет - поздняя взрослость» $[2$, с. 94].

Период средней взрослости, который не связан напрямую с приобретением навыков, характеризуется интеллектуальным развитием. Среднюю взрослость можно назвать периодом третичной социализации (ресоциализации) через профессиональную деятельность, поэтому ведущим мотивом в этом возрасте становится фактор саморазвития.

Анализ научной литературы по вопросу мотивации к обучению показал, что исследования в данной области в основном относятся к периоду ранней взрослости (18-25 лет) (Д. С. Закарлюка [3], А. Р. Дроздикова-Зарипова [4], И. В. Лаврентьева [5], А. В. Осиповская [6], Т. К. Слабко [7], С. А. Шпильберг [8] и др.). Однако проблема особенностей мотивации к обучению в период средней взрослости недостаточно изучена.

\section{МЕТОДЫ}

Для определения особенностей мотивации к обучению нами была выбрана методика Н. Ц. Бадмаевой, основанная на опроснике В. А. Якунина и А. А. Реана [9]. Мотивы учебной деятельности оценивались по 5-ти балльной системе, в которой «5»- соответственно, максимальная значимость мотива, и «1»-минимальная. После оценки испытуемыми приведенных мотивов производится расчет среднего балла, за счет чего выявляются более значимые мотивы.

Также взята разработанная Т. И. Ильиной «Методика изучения мотивации обучения в вузе», основанная на нескольких известных методиках. В методике 
содержатся 3 оценочных шкалы: первая - «приобретение знаний» - характеризует любознательность и стремление к получению знаний; вторая - «получение диплома» - характеризует стремление посредством формального усвоения знаний получить диплом; третья - «овладение профессией» - характеризует стремление к овладению и формированию профессионально важных качеств [10].

Для оценки эффективности обучения, степени удовлетворенности и влияния обучения на уровень реализованных мотивов обучения была выбрана «Анкета оценки обучения» Е. Ветлужских [11], основанная на «Модели оценки эффективности обучения» Д. Киркпатрика [12], состоящей из 4-х шагов [13]: первый шаг - обратная связь, или насколько обучающимся понравился / не понравился учебный процесс (выявляется степень удовлетворенности процессом обучения у обучающегося); второй шаг - обучение - что изучалось? (выявляется у учащегося степень усвоения навыков и знаний); третий шаг - поведение что меняется в рабочей деятельности обучаемого в результате процесса обучения? (выявляется способность обучаемого использовать в работе те навыки и знания, которые он приобрел в процессе обучения); четвертый шаг - результаты - полученные от процесса осязаемые результаты.

Констатирующий и контрольный этапы эксперимента проходили на базе ГКУ Центр занятости населения (ЦЗН) Константиновского района Ростовской области; в эмпирическом исследовании приняли участие 40 человек в возрасте 30-42 лет, проходящие курсы профессионального обучения и дополнительного профессионального образования для безработных граждан по специальностям: автоэлектрик, бухгалтерский учет («1С:Предприятие» и «1С:Управление торговлей»), водитель погрузчика, кладовщик, кондитер. В связи с пандемией некоторые специалисты были вынуждены пройти переобучение, чтобы найти другую работу.

Был проведен теоретический анализ проблемы изучения и проявления особенностей мотивации к обучению в период средней взрослости, апробировались методики для диагностики особенностей и видов мотивов к обучению в период средней взрослости.

По мнению ряда авторов $[14,15,16,17,18]$, учебная успеваемость и активность обучающихся непосредственно зависят от структуры и силы мотивации. Достаточно высокий уровень развития учебной мотивации восполняет у обучающегося недостаточный запас ЗУН и специальных способностей $[19,20]$. Отличительной особенностью мотивации к обучению является преобладание конкурентного, кооперативного и утилитарно-прагматического мотивов в период средней взрослости. 


\section{РЕЗУЛЬТАТЫ}

Рассмотрим результаты проведенного нами экспериментального исследования. Результаты диагностики по «Методике для диагностики учебной мотивации студентов» (А. А. Реан и В. А. Якунин, модификация Н. Ц. Бадмаевой) представлены в таблице 1.

Таблица 1

Результаты провеАенной МетоАИки А^я Аиवгностики Учебной мотивации в периоА среАней взрослости

\begin{tabular}{|l|c|c|}
\hline \multicolumn{1}{|c|}{ Мотив } & Срелний балм & $\begin{array}{c}\text { Ранг мотива } \\
\text { по значимости }\end{array}$ \\
\hline Продрессиональные мотивы & 4,1 & 1 \\
\hline Социальные мотивы & 3,9 & 2 \\
\hline Коммуникативные мотивы & 3,5 & 4 \\
\hline Учебно-познавательные мотивы & 3,4 & 5 \\
\hline Мотивы престижа & 3,4 & 6 \\
\hline Мотивы творческой самореализации & 2,7 & 7 \\
\hline Мотивы избегания & 1,1 & 4 \\
\hline
\end{tabular}

Полученные результаты исследования показали, что на первом месте у обучающихся в возрасте 30-42 лет находятся профессиональные мотивы (средний балл 4,1), основой которых считается то, что выбранная профессия интересна для опрошенных. Все респонденты отметили необходимость обучения для обеспечения успешности в будущей профессиональной деятельности: стать специалистом в данной области и в полной мере использовать имеющиеся у них задатки, способности и склонности к выбранной профессии.

На второе место люди, находящиеся в периоде средней взрослости, ставят социальные мотивы (3,9 балла), т. к., по мнению респондентов, полученные в ходе обучения знания позволят повысить материальное положение за счет продвижения по службе. Менее значимым из составляющих социальных мотивов опрошенные отметили то, что обучение позволит им принести больше пользы обществу и окружающим, членам семьи.

Коммуникативные мотивы опрошенными ставятся на третье место (3,5 балла). Так, в период средней взрослости испытуемые хотят быть уважаемыми окружающими, а знания, полученные в процессе обучения, придают им уверенности и позволяют заводить знакомства, общаться с интересными 
ПЕДАГОГИЧЕСКАЯ ПСИХОЛОГИЯ

людьми. Также респонденты отмечают: чтобы работать с людьми, надо иметь глубокие и всесторонние знания.

Анализ показал, что средний балл 3,4 определен по двум мотивам: престижа и учебно-познавательному. Также следует отметить, что выявлена несущественная разница в количественном соотношении между данными мотивами и коммуникативными мотивами (в последнем случае больше на 0,1 балл).

Рассмотрим особенности мотива престижа. Так, опрошенные отметили, что хотят получить диплом с хорошими оценками, чтобы иметь преимущество перед другими кандидатами на определенную должность, а также быть лучшими среди обучающихся и на хорошем счету у преподавателя, который, в свою очередь, может порекомендовать их на новую должность, найти новое место работы.

Учебно-познавательные мотивы в период средней взрослости характеризуются тем, что полученные знания пригодятся им в профессиональной деятельности, а для этого они должны быть глубокими и прочными. Люди в данном возрасте отмечают, что им нравится учиться, узнавать новое, получать хорошие оценки и отзывы со стороны преподавателя.

Мотивы творческой самореализации стоят на предпоследнем месте (средний балл 2,7); респонденты отмечают, что обучаются для того, чтобы узнавать новое, заниматься творческой деятельностью.

Мотив избегания занял последнее место среди выделенных рангов мотивов по значимости (1,1 балл). Так, только часть опрошенных отметили, что проходят обучение ради того, чтобы не лишиться работы, и вынуждены получать хорошие отметки с этой же целью.

В таблице 2 представлены результаты исследования по методике изучения мотивации обучения Т. И. Ильиной.

Таблица 2

Результаты изучения мотивации обучения

\begin{tabular}{|l|c|c|}
\hline \multicolumn{1}{|c|}{ Шкалы } & Средний балм & $\begin{array}{c}\text { Ранжирование мотива } \\
\text { по значимости }\end{array}$ \\
\hline $\begin{array}{l}\text { Овлаление } \\
\text { профрессией }\end{array}$ & 8,7 & 1 \\
\hline $\begin{array}{l}\text { Приобретение } \\
\text { знаний }\end{array}$ & 8,6 & 2 \\
\hline Получение Аиплома & 8,2 & 3 \\
\hline
\end{tabular}


Анализ полученных результатов исследования показывает высокую значимость получения профессии в период средней взрослости у респондентов. На первое место опрошенные в возрасте 30-42 лет определяют овладение профессией (8,7 балла): респондентам большое удовлетворение доставляет рассказ знакомым о будущей профессии, все их увлечения так или иначе связаны с будущей профессией, высокая зарплата после окончания вуза является для них одним из основных факторов.

На второе место ими ставится приобретение знаний (8,6 балла): респондентами приоритет отдается самостоятельному глубокому изучению специфических профессиональных дисциплин.

Получение диплома является также важным для респондентов в среднем возрасте (8,2 балла). Они считают, что в наше время обязательно иметь высшее образование для продвижения по службе и получения работы.

\section{ОБСУЖДЕНИЕ РЕЗУЛЬТАТОВ}

Таким образом, проведенное исследование показало, что в периоде средней взрослости преобладают профессиональные и социальные мотивы (с разницей 0,2 балла), выражающиеся в повышении материального, нравственного богатства личности посредством повышения профессиональных компетенций. Овладение выбранной профессией способствует самореализации и позволит в дальнейшем принести пользу обществу и их семье.

Далее выдвигаются коммуникативные и учебно-познавательные мотивы, престижа (разница в 0,1 балл). Обучение, по мнению людей, находящихся в периоде средней взрослости, позволяет заводить знакомства и общаться с интересными людьми, приобретать глубокие и прочные знания, которые дают им уверенность в себе, быть конкурентоспособными на рынке труда.

Мотивы творческой самореализации выделяются только частью респондентов: так, по их мнению, обучение позволяет получить новые знания, которые будут реализовываться ими в творческой деятельности.

Менее всего в группе респондентов среднего возраста выражен мотив избегания: так, только небольшая часть опрошенных отметили, что их обучение вынужденное.

Анализ результатов исследования мотивации обучения в период средней взрослости показал, что респонденты считают важными получение профессиональных знаний, овладение профессией и получение диплома об обучении.

В таблице 3 представлены результаты анкетирования респондентов среднего возраста после пройденного обучения в ГКУ Центр занятости населения Константиновского района Ростовской области. 
ПЕДАГОГИЧЕСКАЯ ПСИХОЛОГИЯ

Таблица 3

Результаты анкетирования об эффективности пройАенного обучения

\begin{tabular}{|l|c|}
\hline \multicolumn{1}{|c|}{ Вопрос } & $\begin{array}{c}\text { \% эорорективности/ } \\
\text { результативности }\end{array}$ \\
\hline Актуальность полученных знаний & $95 \%$ \\
\hline Понятность изложенного материала & $96 \%$ \\
\hline $\begin{array}{l}\text { Насколько обучение } \\
\text { способствовало } \\
\text { совершенствованию мичных } \\
\text { качеств? }\end{array}$ & $96 \%$ \\
\hline Новизна полученной инорормации & $97 \%$ \\
\hline $\begin{array}{l}\text { Практическая ценность материала, } \\
\text { применимость Аля работы }\end{array}$ & $97 \%$ \\
\hline $\begin{array}{l}\text { Насколько обучение } \\
\text { способствовало развитию навыков? }\end{array}$ & $97 \%$ \\
\hline $\begin{array}{l}\text { удовлетворенность полученными } \\
\text { материалами (Аокументацией) }\end{array}$ & $97 \%$ \\
\hline $\begin{array}{l}\text { Соответствие солержания курса } \\
\text { ожиланиям }\end{array}$ & $98 \%$ \\
\hline $\begin{array}{l}\text { Соответствие солержания курса } \\
\text { программе }\end{array}$ & \\
\hline
\end{tabular}

При проведении анализа по результатам анкетирования выявлены результативность и эффективность обучения. Согласно ответам респондентов, обучение соответствует содержанию курса, полученные знания актуальны, изложенный материал понятен, полученная информация обладает новизной и практической ценностью, способствует совершенствованию личностных качеств.

\section{ЗАКЛЮЧЕНИЕ}

Таким образом, проведенное исследование позволило выявить высокий уровень мотивации к обучению в период средней взрослости. Ведущими 
мотивами являются (по мере убывания): профессиональные (возможность овладеть профессией, получить новые знания), социальные, коммуникативные, учебно-познавательные, мотивы престижа (иметь диплом / второй диплом), творческой самореализации. В целом можно говорить о высокой эффективности обучения лиц, находящихся в периоде средней взрослости.

Анализ результатов экспериментального исследования показал, что в период средней взрослости в первую очередь преобладают профессиональные и социальные мотивы, выражающиеся в повышении материального, нравственного богатства личности посредством повышения профессионализма. Профессию они выбирают осознанно, основываясь на анализе своих возможностей и задатков. Обучающиеся планируют, что в дальнейшем профессия позволит приносить пользу обществу.

На второй план выдвигаются мотивы: коммуникативные, учебно-познавательные мотивы, а также мотивы престижа. Обучение, по мнению людей среднего возраста, позволяет заводить знакомства и общаться с интересными людьми, повысить уровень профессиональных компетенций. Далее идут мотивы творческой самореализации, выделяемые только некоторыми респондентами.

Мотивами обучения служат: овладение профессией, приобретение знаний и получение диплома.

Также анализ результатов исследования показал высокий уровень эффективности и результативности обучения у данной категории граждан, находящихся в периоде средней взрослости.

\section{ЛИТЕРАТУРА}

1. Pugh K. J., Bergstrom C. M., Spencer B. Profiles of transformative engagement: Identification, description, and relation to learning and instruction // Science Education. 2017. Vol. 101, Issue 3. P. 369-398. DOI: 10.1002/sce.21270

2. Психология развития / Под ред. А. К. Болотовой и О. Н. Молчановой. М.: ЧеРо, 2005. 524 с.

3. Закарлюка Д. С., Галушка М. А. Анализ уровня учебной мотивации работающих студентов // Международный студенческий научный вестник. 2018. № 5. URL: http://eduherald.ru/ru/article/view?id=18911 (дата обращения: 01.12.2020).

4. Дроздикова-Зарипова А. Р., Муртазина Э. И., Касимова Р. Ш. Специфика учебной мотивации у работающих студентов - будущих педагогов-психологов // Казанский педагогический журнал. 2017. № 3. С. 56-61.

5. Лаврентьева И. В., Игнатенко К. М. Выявление учебно-профессиональной мотивации в процессе обучения в вузе (на материале тестирования студентов-дефектологов 1-3 курсов) // Молодой ученый. 2015. № 6 . С. 778-783. 
6. Осиповская А. В. К вопросу о мотивации учебной деятельности студентов // Экономический журнал. 2013. № 2. С. 89-93.

7. Слабко Т. К. Особенности мотивации студентов с разным уровнем учебной успешности // Материалы VII Международной студенческой научной конференции «Студенческий научный форум». URL: scienceforum. ru/2015/article/2015012473 (дата обращения: 01.12.2020).

8. Шпильберг С. А. Особенности формирования мотивации к учебной деятельности студентов первого курса различных направлений обучения вуза // Молодой ученый. 2015. № 23. С. 908-911.

9. Методика для диагностики учебной мотивации студентов (А. А. Реан и В.А. Якунин, модификация Н.Ц. Бадмаевой) // Gurutestov.ru. URL: http:// www.gurutestov.ru/test/12 (дата обращения: 01.12.2020).

10. Методика изучения мотивации обучения в вузе Т. И. Ильиной // TECТотека. URL: testoteka.narod.ru/ms/1/05.html (дата обращения: 01.12.2020).

11. Ветлужских Е. Модели критериальной оценки результатов обучения // Бизнес Школа «Эксперт». URL: https://moscow-expert.ru/articles/article/13/ index.html (дата обращения: 01.12.2020).

12. Kirkpatrick D. L., Kirkpatrick J. D. Implementing the four levels: A practical guide for effective evaluation of training programs. San Francisco: BerrettKoehler Publishers, 2007. 153 p.

13. Четырехуровневая модель оценки Киркпатрика (Clark D. Kirkpatrick's Four Level Evaluation Model) / пер. Э. Бабушкина. URL: http://hrm. ru/chetyrekhurovnevaja-model-ocenki-kirkpatrika (дата обращения: 01.12.2020).

14. Бордовская Н. В., Реан А. А. Педагогика. Учебник для вузов. СПб.: Питер, 2000. 304 c.

15. Гордашников В. А., Осин А. Я. Образование и здоровье студентов медицинского колледжа: монография. М.: Академия Естествознания, 2009. 395 с.

16. Ильин Е. П. Мотивация и мотивы. СПб.: Питер, 2004. 508 с.

17. Прохорова М. В., Прохоров В. М. Возрастная динамика смыслообразующих мотивов трудовой деятельности // Современные исследования социальных проблем (электронный научный журнал). 2015. № 6. С. 256-269.

18. Якунин В. А. Психология учебной деятельности студентов. М.: Логос, 1994. $156 \mathrm{C}$.

19. Cilliers E. J. The challenge of teaching generation Z // International Journal of Social Sciences. 2017. Vol. 3, Issue 1. P. 188-198.

20. Jukes I., SchaafR. L. A brief history of the future of education: Learning in the age of disruption. Corwin, 2019. DOI: $10.4135 / 9781544355061$ 


\section{REFERENCES}

1. Pugh K. J., Bergstrom C. M., Spencer B. Profiles of transformative engagement: Identification, description, and relation to learning and instruction. Science Education, 2017, V. 101, Issue 3, pp. 369-398. DOI: 10.1002/sce.21270

2. Bolotova A. K., Molchanova O. N. (Eds.). Psychology of development. Moscow, CheRo Publ., 2005. 524 p. (in Russ.).

3. Zakarlyuka D. S., Galushka M. A. Analysis of the level of educational motivation of working students. Mezhdunarodnyi studencheskii nauchnyi vestnik = International Student Scientific Bulletin, 2018, no. 5. Available at: http://eduherald.ru/ru/article/view?id=18911 (Accessed 01 December 2020). (in Russ.).

4. Drozdikova-Zaripova A. R., Murtazina E. I., Kasimova R. Sh. Educational motivation specifics at working future educational psychologists. Kazanskii pedagogicheskii zhurnal = Kazan Pedagogical Journal, 2017, no. 3, pp. 56-61. (in Russ.).

5. Lavrent'eva I. V., Ignatenko K. M. Identification of educational and professional motivation in the process of studying at the University (based on the material of testing students-defectologists of 1-3 courses). Molodoi uchenyi = Young Scientist, 2015, no. 6, pp. 778-783. (in Russ.).

6. Osipovskaya A. V. On the issue of motivation of students' educational activities. Ekonomicheskii zhurnal, 2013, no. 2, pp. 89-93. (in Russ.).

7. Slabko T. K. Features of motivation of students with different levels of academic success. Materials of the VII International Student Scientific Conference "Student scientific forum". Available at: https://scienceforum. ru/2015/article/2015012473 (Accessed 01 December 2020). (in Russ.).

8. Shpil'berg S. A. Features of formation of motivation to educational activity of first-year students of various directions of higher education. Molodoi uchenyi = Young Scientist, 2015, no. 23, pp. 908-911. (in Russ.).

9. Methodology for diagnostics of students' learning motivation (A. A. Rean \& V. A. Yakunin, modification by N. Ts. Badmaeva). Gurutestov.ru. Available at: http://www.gurutestov.ru/test/12 (Accessed 01 December 2020). (in Russ.).

10. Methodology for studying motivation in higher education by T. I. Il'ina. TESToteka. Available at: http://testoteka.narod.ru/ms/1/05.html (Accessed 01 December 2020). (in Russ.).

11. Vetluzhskih E. Models for criteria-based evaluation of learning outcomes. Business School "Expert". Available at: https://moscow-expert.ru/articles/ article/13/index.html (Accessed 01 December 2020). (in Russ.).

12. Kirkpatrick D. L., Kirkpatrick J. D. Implementing the four levels: A practical guide for effective evaluation of training programs. San Francisco, Berrett-Koehler Publishers, 2007. $153 \mathrm{p}$. 
ПЕДАГОГИЧЕСКАЯ ПСИХОЛОГИЯ

13. Clark D. Kirkpatrick's Four Level Evaluation Model (transl. by E. Babushkin). Available at: http://hrm.ru/chetyrekhurovnevaja-model-ocenki-kirkpatrika (Accessed 01 December 2020). (in Russ.).

14. Bordovskaya N. V., Rean A. A. Pedagogy. Textbook for universities. Saint Petersburg, Piter, 2000. 304 p. (in Russ.).

15. Gordashnikov V. A., Osin A. Ya. Education and health of medical college students: monograph. Moscow, Akademiya Estestvoznaniya, 2009. 395 p. (in Russ.).

16. Il'in E. P. Motivation and motives. Saint Petersburg, Piter, 2004. 508 p. (in Russ.).

17. Prokhorova M. V., Prokhorov V. M. The age dynamics of sense-making motives of labor activity. Sovremennye issledovaniya sotsial'nykh problem = Modern Research of Social Problems, 2015, no. 6, pp. 256-269. (in Russ.).

18. Yakunin V. A. Psychology of educational activity of students. Moscow, Logos, 1994. 156 p. (in Russ.).

19. Cilliers E. J. The challenge of teaching generation Z. International Journal of Social Sciences, 2017, V. 3, Issue 1, pp. 188-198.

20. Jukes I., Schaaf R. L. A brief history of the future of education: Learning in the age of disruption. Corwin Publ., 2019. DOI: 10.4135/9781544355061 